\title{
Angiomodulatory properties of Rhodiola spp. and other natural antioxidants
}

\author{
DOROTA M. RADOMSKA-LEŚNIEWSKA I, PIOTR SKOPINSSKI, , BARBARA J. BAEAN \\ AGATA BIAŁOSZEWSKA ${ }^{1}$, JAROSŁAW JÓŹWIAK ${ }^{1}$, DARIUSZ ROKICKI', \\ EWA SKOPIŃSKA-RÓŻEWSKA ${ }^{4,5}$, ANNA BORECKA ${ }^{5}$, AGATA HEVELKE \\ ${ }^{1}$ Department of Histology and Embryology, Medical University of Warsaw, Warsaw, Poland \\ ${ }^{2}$ Second Department of Ophthalmology, Medical University of Warsaw, Warsaw, Poland \\ ${ }^{3}$ Department of Immunology, Biochemistry and Nutrition, Medical University of Warsaw, Warsaw, Poland \\ ${ }^{4}$ Department of Pathology, Medical University of Warsaw, Warsaw, Poland \\ ${ }^{5}$ Laboratory of Genetic Epidemiology and Department of Regenerative Medicine, Military Institute of Hygiene and Epidemiology, Warsaw, \\ Poland
}

\begin{abstract}
Disturbances of angiogenesis and oxidative stress can lead to many serious diseases such as cancer, diabetes or ischemic heart disease. Substances neutralizing oxidative stress are known as antioxidants. They can affect angiogenesis process also, and thus, they modulate therapy results. Antioxidants become more and more frequently used in order to maintain homeostasis of the organism and diminish the risk of disease. Herein, we introduce some antioxidant preparations of natural plant origin (Rhodiola, Aloe vera, Resveratrol, Echinacea, Plumbagin) and antioxidant supplements (Padma 28, Reumaherb, Resvega). Analyses of their angiogenic properties, their multidirectional molecular effect on angiogenesis as well as medical application are within the scope of this review. Most of presented preparations down regulate neovascularization. They can be safely administered to patients with abnormally high angiogenesis. Rhodiola modulates, and Echinacea, Aloe vera and Plumbagin inhibit tumour-related angiogenesis in vitro and in vivo (animal models). Resveratrol and Resvega reduce neovascularization in the eye and may be applicable in eye disorders. Padma 28 preparation exhibits angioregulatory activity, decreasing high angiogenesis of cancer cells and increasing physiological angiogenesis, therefore can be used in therapy of patients with various disturbances of angiogenesis. Antioxidant application in the case of angiogenesis-related diseases should take into consideration angiogenic status of the patient.
\end{abstract}

Key words: natural antioxidants plant origin, angiomodulatory properties.

(Centr Eur J Immunol 2015; 40 (2): 249-262)

\section{Introduction}

Oxidative stress reflects an imbalance between the systemic manifestation of reactive oxygen species (ROS) and biological system's ability to readily detoxify the reactive intermediates or to repair the resulting damage. Oxidative stress is thought to be involved in the development of e.g., cancer, Parkinson's disease, Alzheimer's disease, atherosclerosis, heart failure, myocardial infarction [1, 2]. However, short-term oxidative stress may also be important in prevention of aging by induction of a process named mitohormesis.

Angiogenesis, the process of new blood vessel formation, may contribute to pathogenesis of many severe diseases that characterized disturbances of angiogenesis e.g., cancer, stroke, ischemic heart disease, neurodegenerative diseases, atherosclerosis or hypertension. Contribution of these two processes in the development of severe civilization diseases implicates close relationship between them [1-5].

Substances neutralizing consequences of oxidative stress are known as antioxidants. Administered to the patients, they are able to restore disturbed human health influencing mainly redox status. Antioxidant defense system protects the cell from ROS toxicity and oxidative stress. Antioxidants can also affect angiogenesis and thus modulate therapy course and results.

Patients' and doctors' interest in natural medicines that restore the homeostasis of organism is currenly evident. Therefore the knowledge of antioxidant angiogenic prop-

Correspondence: Prof. Ewa Skopińska-Różewska, Military Institute of Hygiene and Epidemiology, Kozielska 4, 01-163 Warsaw, Poland, e-mail: ewaskop@hotmail.com 
erties and their clinical implication seem to be useful in medical practice.

\section{Angiogenesis}

Formation of new blood vessels from preexisting ones is known as angiogenesis. It is a part of both physiological and pathological processes. Angiogenesis is necessary for menstrual cycle, embriogenesis and wound healing. Disturbances of this process can lead to serious diseases, characterized by too high level of angiogenesis, such as cancer, psoriasis, endometriosis, rheumatoid arthritis, age-related macular degeneration (AMD), or too low level observed e.g., diabetes mellitus, stroke, ischemic heart disease, atherosclerosis, hypertension or wound healing.

Angiogenesis is usually triggered by hypoxia. Hypoxic response is mediated through a family of hypoxia-inducible factors (HIFs). The best studied protein is HIF1- $\alpha$ which stimulates secretion of vascular endothelial growth factor A (VEGF A) and its receptor, effectively promoting angiogenesis. VEGF-A is the key member of a VEGF/ PDGF super family. VEGFs stimulate vascular permeability and endothelial cell (EC) proliferation, migration, and survival. It was shown, that VEGFR2/KDR/Flk-1 receptor is the main and most important VEGFs receptor mediating almost all of the known cellular responses to VEGF [6, 7].

Various pro- and anti- angiogenic cytokines interplay during the process of angiogenesis. There is negative feedback regulation between PAI-1 and its potent activator TGF-beta in endothelial cells [8].

Angiogenesis process is normally controlled by angiogenesis inhibitors such as angiostatin, endostatin and thrombospondin, but also VEGFR1/Flt-1 receptor, often expressed as a soluble splice variant (sFlt-1) that neutralize VEGF, inhibiting in such way process of angiogenesis. Besides, also pro-angiogenic factors (e.g. VEGF, fibroblast growth factor-1 (FGF-1, bFGF) play the regulatory function in neovascularization, activating endothelial cells and triggering this process. New vessels are formed by a series of complex morphological and biochemical events in various stages. Activated EC secrete proteases, mainly matrix metalloproteinases (MMPs), responsible for the degradation of the base membrane and remodeling of the extracellular matrix. This causes important changes in cell-adhesion mechanisms, and leads to migration, and proliferation of endothelial cells, which results in the formation of endothelial capillary tubes [9]. Stabilisation of a new capillary is ensured by basement membrane formation and pericyte recrutation [4]. During this stage the function of platelet-derived growth factor (PDGF), a mitogen and chemoattractant of pericytes, is arised. Tranforming growth factor (TGF- $\beta$ ) and FGF-1 plays a role in differentiation of these cells. Furthermore, growth factors known as a angiopoetins (Ang) regulate maturation and structure of new vessels. In angiogenesis related diseases balance between pro- and anti-angiogenic proteins is disturbed.

Knowledge concerning angiogenic properties of medical preparations administered to the patients seems to be very important for therapy results.

\section{ROS and angiogenesis relationship}

ROS and reactive nitrogen species (RNS), e.g. nitric oxide (NO), so called free radicals, are highly chemically reactive forms of oxygen that have the potential to injure different cells. The three major species are hydrogen peroxide, superoxide, and hydroxyl radicals. There are many enzymes in the cells that produce ROS as a byproduct of the main catalytic function e.g. cytochrome $\mathrm{P} 450$ reductase, nitric oxide synthases (NOSs), xanthine oxidase. However, generation of superoxide/ROS as primary function is evident only in NADPH oxidases. Free radicals play an important role in many cellular processes. At low level ROS modulate gene expression, cell proliferation and they can induce transrciption and apoptosis. Furthermore, they contribute to inflammatory and angiogenesis processes. $[10,11]$. They trigger some transcription factors e.g. nuclear factor $\kappa \mathrm{B}(\mathrm{NF}-\kappa \mathrm{B})$ or activator protein 1 (AP-1) [12]. However, at high concentrations, free radicals can be dangerous. Overproduction of ROS results in oxidative stress, and can be an important mediator of damage all major cell components, e.g. cell membranes, proteins, lipids and even DNA $[3,13]$.

Many studies have shown that endothelial cells produce ROS through NADPH oxidase known as an NOX. It has been reported to regulate physiological and pathological angiogenesis. They influence e.g. production of VEGF and its receptor, MMPs and some transcripion factors (NF$\kappa \mathrm{B}, \mathrm{AP}-1, \mathrm{Stat} 1 / 3, \mathrm{E} 2 \mathrm{~F}, \mathrm{CREB}, \mathrm{HIF}-1)$ that contribute to angiogenesis process $[14,15]$.

However, free radicals play an unclear role in neovascularization, because on one hand, high concentration of ROS causes oxidative stress and leads to apoptosis, on the other, low levels function as signaling molecules that mediate the proliferation and migration of the endothelial cells. It is important in spreading of angiogenesis [16].

It was observed that different kinds of cells can produce VEGF as a response to exogenous ROS [11, 17]. Exogenous ROS was able to initiate pro-angiogenic changes in EC such as cytoskeleton reorganization. They also provoke proliferation, migration and tubular morphogenesis of these cells [18].

Kim et al. [19] study revealed that $\mathrm{H}_{2} \mathrm{O}_{2}$ induced by Ang-1 influences neovascularization in vivo. ROS level was also closely related with wound healing and other physiological repair processes in vivo [20]. Another study exerted participation of $\mathrm{H}_{2} \mathrm{O}_{2}$ in proliferation and migration of EC and tubulogenesis activated by lymphocytes [16]. Furthermore, Nijmeh et al. [10] demonstrated contribution 
of ROS in angiogenesis caused by ischemia in a mouse model.

Understanding the role of free radicals in triggering new blood vessel formation may lead to their use as potential targets for treatment of angiogenesis-dependent diseases. Many natural products from diet contain important combinations of ingredients that may help to modulate the effects exerted by oxidation.

\section{Antioxidants}

"Substances present at low concentration, compared to oxidizable substrate which significantly delays or prevents the oxidation of the substrate are called antioxidants" [21]. They neutralize or block the activity of free radicals, thus preventing tissues and cells from damage. Some antioxidants (endogenous) are made naturally in the body, but others should be obtained from exogenous (external) sources, including the diet (fruits, vegetables and grains), and different natural dietary supplements. Many studies have shown that exogenous antioxidants can help prevent the free radical damage associated with inflammatory diseases and development of cancer. It has been shown that antioxidants are able to prevent some types of free radical damage associated with cancer development in animal models. Therefore, the question issue whether taking dietary antioxidant supplements can help lower the risk of developing severe diseases in humans, and how they affect the new blood vessel formation, is still under investigation [22].

\section{Natural antioxidants}

The main sources of antioxidants belonging to this group are plants, but also microorganisms, fungi or animals [23]. Natural antioxidants are under intensified studies, as they constitute a huge group of substances with broad spectrum of application. The highest number of available preparations with antioxidative properties belongs to this group.

Plant-based immune stimulation, its antioxidative and anti-carcinogenic properties, provides an alternative to conventional therapy of cancer, inflammatory and infectious diseases, especially in immunocompromised patients. Conventional chemotherapy may also often result in undesirable effects $[13,22,24]$. There are plenty of natural products that found practical application in therapy [25, 26]. For example green tea (Camellia sinensis), thanks to its multiple beneficial health effects, is being increasingly consumed in beverages. Green tea polyphenols have been shown to have anti-proliferative activity against a wide variety of cell lines. Green tea contains epigallocathechin-3-gallate (EGCG), a polyphenol that is an antioxidant with chemopreventive and chemotherapeutic actions. As a diet supplement, EGCG is also prepared in capsules as green tea extract (GTE). Antiangiogenic and antioxidant properties of garlic and its compounds (allicin) were described by Chan et al. [27]. The authors emphasized cardiovascular benefits of allicin. The polyphenols in red wine, chocolate, peanuts, blueberries and cranberries have been shown to have antioxidant beneficial effects on health [28].

The wide group of natural antioxidants comprise NOX inhibitors. They are present in many fruits and vegetables. Various compounds can inhibit NADH oxidases, for example a plant alkaloid berberine. Suppression of NOX activity was observed in macrophages treated with this alkaloid [29]. Emodin, a component extracted from Rheum rhabarbarum reduced ROS generation [30], similarly to treatment with 3-(4'- hydroxyl-3',5'-dimethoxyphenyl) proppionic acid, ellagic acid [31], and apocynin isolated from Picrorhiza kurroa [32].

Free radicals play an important role in the pathogenesis of diseases of civilization such as diabetes, obesity, hypertension, atherosclerosis, or cancer. Knowledge about the dangers that free radicals pose leads investigators to seek substances that support body's natural antioxidative defenses. One particularly promising area of research is the study of secondary metabolites derived from plants with recognized therapeutic effects.

\section{Rhodiola}

One group of plants whose root extracts exhibit antioxidant activity are plants of the Rhodiola genus [33].

The genus Rhodiola (Crassulaceae) includes more than 200 recognised species (out of which approximately 20 are used in traditional medicine). The most intensively studied species is Rhodiola rosea ( $R$. rosea). $R$. rosea grows in the mountains of Central Asia, North America and Europe. The medicinal raw material (rhizome with roots) is used in traditional folk medicine in Europe, mainly in Russia and Scandinavia. Modern research has revealed the antioxidative, adaptogenic, anti-stress, anti-microbial, immune-modulating and angiomodulating properties of Rhodiola rosea. Many other species are still being examined by researchers. These include Rhodiola crenulata - a sacred plant of Tibetan monks; Himalayan Rhodiola imbricata; as well as originated in China and Tibet Rhodiola Kirilowii that is used in traditional Chinese medicine as a cure for altitude sickness (commonly used by mountain climbers, aviators and astronauts). One of the least researched species is Rhodiola quadrifida, which is used in Mongolian traditional medicine. The roots and rhizomes of Rhodiola kirilowii and Rhodiola rosea, which were being imported from Siberia and Tibet were highly valued in ancient China and used by imperial medics.

In Poland, Rhodiola rosea plants grow mainly in national parks in the Sudetes, the Tatras and the Bieszczady mountains. They are also grown, like the other less well 
known in Europe Rhodiola kirilowii at the Institute of Natural Fibres and Medicinal Plants in Plewiska near Poznan.

Plants of Rhodiola genus are potent antioxidants and adaptogens that increase resistance to stress. They also have antiarrhythmic and cardioprotective properties. The cardioprotective effects of Rhodiolas extend to the protection of the heart against stress factors that cause damage to the muscle by free radicals. Anti-cancer properties of Rhodiola involve, among other things, the protection of tissues against free radicals and weak and medium-strength mutagens [34-44].

Beneficial effects of remedies containing extracts of Rhodiola spp. on human organisms are due to the presence in them of many biologically active substances. Among these substances are the tannins, fenyloethanoids (salidroside, tyrosol), phytosterols, flavonoids (kaempferol,quercetin, catechins, proanthocyjanidins), terpenoids, phenylpropanoids, phenolic acids and phenolic glycosides, as well as other groups of organic compounds. A trait of Rhodiola rosea species are glycosides of cinnamic alcohol (Rosin, Rosavin, rosarin) that are also obtainable in in vitro cultures of R. kirilowii; for R. quadrifida and R. heterodonta - mongrhoside and rhodiocyanoside [45-50].

Anti-oxidant effects of methanol extracts of Rhodiola imbricata were connected with phenolic compounds, which were found in high concentrations in the tissues of the plant [51]. The ability of antioxidant phenols and polyphenols was also described by many other researchers who indicated caffeic acid and flavonoids present in Rhodiola [52].

Salidroside and p-tyrosol present in Rhodiola also exhibit antioxidant activity [53, 54]. According to Covas et al., tyrosol, which is capable of binding low density lipoproteins (LDL) could be an effective weapon in preventing atherosclerotic processes. [55] Unfortunately, recently conducted experiments by Vlachogianni et al. (2015) did not confirm the anti-oxidative properties of tyrosol [56].

Other polyphenols, gallic acid and methyl gallate inhibited the oxidative stress in human endothelial cells exposed to hydrogen peroxide [57]. Serrano et al. described the dualistic behavior of gallic acid, dependent on the conditions of the trial, with a set of human endothelial cells derived from microvascular (HMEC-1). In the cultures that contained peroxidase, gallic acid behaved as a pro-oxidant, causing damage to the cells. Once hydrogen peroxide was added gallic acid behaved as an anti-oxidant, inhibiting the free radicals created during the oxidasing cycle [58].

The antioxidant and cyto-protective activity of water and alcoholic extracts of Rhodiola imbricata in cultured human macrophages treated with tert-BHP oxidant was observed. Both types of extracts at a concentration of 250 micrograms per milliliter inhibited the formation of free radicals and apoptosis [59].

In experiments on rats, quercetin and catechins, flavonoids also present in extracts of roots of Rhodiola plants, inhibited lipid oxidation induced by mercuric chloride [60].

Quercetin (QU) is natural flavonoid with minor toxic side-effects, with anti-oxidant, anti-inflammatory and anti-angiogenic properties. This natural compound would be an adjuvant natural drug for treatment of rheumatoid arthritis, through inhibiting the activities of VEGF, bFGF, MMP-2 and other cytokines [61].

Quoted data indicate that many substances in Rhodiola plants have a high anti-oxidative capacity and in the future might be helpful in combating diseases of inflammatory etiology as well as those associated with overproduction of free radicals.

An important feature of the extracts of Rhodiola plants is the ability to inhibit processes of creating new blood vessels (angiogenesis). This process is essential for tumor progression, since the newly formed cell tissue inside the tumor has a much restricted access to nutrients and oxygen. Inhibition of this process significantly slows down the growth rate of the primary tumor and reduces the likelihood of metastasis.

The study, which began in Poland at the end of the previous century was continued during the last fifteen years, on different aspects of water and water-alcoholic extracts of rhizomes and roots $R$. rosea, $R$. kirilowii and $R$. quadrifida. It has shown a low acute toxicity and the lack of toxic effects in the sub-chronic studies of toxicity (LD50 $=5 \mathrm{~g} / \mathrm{kg}$ ) in test animals. It also confirmed a broad-spectrum of antimicrobial activity against bacteria and fungi . Antioxidant, adaptogenic and anti-inflammatory $[33,62,63]$ and for the first time in history the anti-angiogenic effects were examined. Despite some differences between plant species and the method of preparing the extracts, they stimulated specific and nonspecific immunity in vivo and in vitro [64-78], and inhibited the reaction of skin neovascularization which was induced in mice through an implantation of syngeneic tumor cells (except aqueous extract of Rhodiola kirilowii) or homogenate of human kidney cancer. A similar effect was observed in mice which were being fed with salidroside and rosavin for three days post-implantation of tumor cells [79-83]. In experiments conducted in vitro, in cell cultures of mouse endothelial cells in the presence of L-1 sarcoma, the hydro-alcoholic extract of $R$. kirilowii inhibited migration and increased proliferation of endothelial cells. Both extracts inhibited proliferation of tumor cells. At the same time the aqueous extract stimulated both proliferation and migration of endothelial cells [83].

Some data suggest that antioxidants affect physiological angiogenesis in vivo through regulation of nitric oxide synthase (NOS) expression and activity [84].

Example of other natural drug which inhibit migration and invasiveness of endothelial cells in very low concentration, which did not affect endothelial cells proliferation, is Paclitaxel [85]. 
Extracts of Rhodiola kirilowii are rich in flavonoids, ubiquitous plant secondary products. They are potent antioxidants in vitro. However, their antioxidant effect in vivo is less documented, moreover, in some situations they behave as pro-oxidants [86]. The in vitro antioxidant activity of flavonoid depends on the configuration and total number of hydroxyl groups on its core structure. Polymerization of flavonoid monomers increased their activity. Possibly, radical scavenging activity of $R$. kirilowii extracts is mainly connected with their content of quercetin and catechins [87].

\section{Echinacea}

Echinacea sp. (Asteraceae), is one of the most important world medicinal herbs, widely used for the treatment of different diseases. Its extracts contain many compounds with proved immunomodulatory, antioxidant and anti-inflammatory activities. Use of Echinacea purpurea (purple coneflower) and Echinacea angustifolia (narrow-leaved purple coneflower), herbs native to North American prairies, has a long history. North American Indians used these plants internally and externally as antiseptic, anti-inflammatory and analgesic drug.

Access to herbal remedies is easy and unrestricted. They are often introduced to the market as food supplements and people regard them as safe. That is why our group decided to examine and describe some extracts of different Echinacea sp. on animal models. These remedies were used in our experiments at the doses recalculated from the doses recommended for humans. In numerous research works we reported that Echinacea purpurea extracts enhance immunity in mice and stimulate various functions of human blood leukocytes in vivo. Besides, they influence angiogenesis, depending on the form of extract and herb or part of the herb (powder, water and alcoholic solutions obtained from E. purpurea, E. angustifolia, E. palida). We have proved that Echinacea purpurea extract diminished neovascular reaction induced in mouse skin by human cancer cells . Echinacea purpurea-derived drug diminishes also neovascular reaction induced in mouse skin by syngeneic L-1 sarcoma cells and reduces VEGF concentration in L1 sarcoma tumor tissue, not affecting tumor mass and tumor cell angiogenic activity [88-95].

VEGF production and function may be suppressed by various polyphenolic compounds, among them phenolic acids. Echinacea purpurea extracts contain cichoric, caftaric, chlorogenic and caffeic acids that also have antioxidative and antiangiogenic activity. Using herbal remedies including Echinacea by pregnant women is popular, because they consider them as curative and safe. Moreover, women often are not conscious of the dangers connected with such remedies and therefore they usually do not inform their doctors about the use of herbal remedies during pregnancy and lactation. However, data regarding safety of this kind of treatment are uncertain. Some papers (mice model) indicate that consuming Echinacea may promote spontaneous abortions [96]. By influencing very important mechanism during fetal development as angiogenesis, some Echinacea drugs can lower the number of embryos and significantly diminish the VEGF and bFGF content in embryonic tissue. Fortunately, trials on pregnant women who were administered Echinacea preparation during the first trimester of pregnancy show that it does not cause major malformation [97]. However, these findings have not been thoroughly confirmed, so they require further studies.

\section{Aloe vera}

Aloe sp. (Liliaceae) probably originates from Northern Africa. It can be found growing in the tropical climates [98]. Presently, this plant is cultivated in many countries, including Poland [99]. Traditionally, Aloe vera was used for treating various human illnesses, including hypertension, gastrointestinal ailments, musculoskeletal ailments, diabetes, asthma, epilepsy, burns, wound healing, and frostbite [100, 101]. A. vera was used as a panaceum, or cure-all in many cultures, especially in India. The plant is used for cosmetic, medicinal, and nutraceutical purposes mainly thanks to its antioxidant properties [102].

Chemical compounds in the Aloe sp. are typically isolated from two parts: latex and gel [103]. Biological effects of the compounds extracted from aloe gel, e.g., acemmanan and B-sitosterol were reported. The polysaccharide acemannan contains $\beta$ - $(1,4)$-linked acetylated mannan which is thought to be responsible for immunomodulating and anti-viral properties [104]. Study on a mice model shows also its anti-tumor activity [105]. $\beta$-sitosterol assures cardiovascular protection, acting through increase of antioxidant defense system and through lowering of the serum cholesterol level in humans [106]. $\beta$-sitosterol exerts proangiogenic effects. Lee et al. [107] obtained active fraction of $\beta$-sitosterol which increased the proliferation of calf pulmonary artery endothelial (CPAE) cells (in vitro). Additionally, this fraction induced CPAE cells to invade type 1 collagen gel and form capillary-like tubes. The effect on the mRNA expression of proteolytic enzymes (which are key participants in the regulation of extracellular matrix degradation) was investigated by northern blot analysis. Active fraction enhanced mRNA expression of urokinase-type plasminogen activator (u-PA), MMP-2, and membrane-type MMP (MT-MMP) in CPAE cells, whereas the expression of plasminogen activator inhibitor-1 (PAI-1) mRNA was not changed.

A. vera is commonly associated with the healing of burns. However, the trials in which A. vera was used to treat burn wounds show no scientific evidence of this therapy [108].

A. vera was also used to treat diabetes thanks to its ability to reduce blood glucose levels and to reduce blood 
lipid levels in patients exhibiting hyperlipidaemia [100]. Parihar et al showed that the administration of A. vera extracts diminished oxidative damage in the brains of sptreptozotocin-induced diabetic rats, probably by an antioxidant mechanism [109]. Some trials show that $A$. vera may be useful in lowering high cholesterol and other risk factors associated with heart disease, though the mechanism of action is unknown. Can et al. [110] administered A. vera extract to patients for $12 \mathrm{wks}$ and found that total serum cholesterol levels, triglycerides, and low-density lipoproteins were reduced. In another study, 5000 patients with symptoms of heart disease who consumed bread prepared with A. vera gel two times a day for three months, showed marked reduction in serum total lipids, cholesterol, and triglycerides [111].

Our group performed some experiments on the basis of tumor-induced cutaneous angiogenesis (TIA) and lymphocyte-induced angiogenesis test (LIA). These tests are a valuable method for in vivo quantitative evaluation of activity of various pro- and anti-angiogenic compounds. The in vivo effect of Bioaron C (containing A. arborescens, Aronia melanocarpa, Acidum ascorbicum, Phytopharm Klęka S.A, Poland) in daily dose of 30 or $90 \mu$, on specific cellular and humoral immunity in mice was studied. The results show the evidence of stimulatory activity of the above-mentioned remedies in mice [112]. Similar effects were also seen after oral administration of Aloe vera gel in mice model [113]. We also examined in vivo effect of three commercially available preparations of aforementioned plants on the neovascular reaction observed after intradermal injection of syngeneic sarcoma or xenogeneic (human) lung and kidney cancer cells [114]. We have shown that Aloe sp. and cranberry preparations acted as tumor angiogenesis inhibitors. As the extension of these studies, it would be prudent to compare anti-angiogenic potential of the assessed preparations with anti-angiogenic compounds with clinically confirmed anti-cancer efficiency. This would facilitate reasoning about potential efficiency of these plant extracts, particularly in immunocompromised cancer patients. In this paper we presented evidence that, on top of their immunostimulatory properties, two $A$. arborescens remedies (Biostymin, and Bioaron C) behave as tumor angiogenesis inhibitors, which would be of great value in adjunctive therapy of patients with tumors, especially those immunocompromised after standard treatment. All doses of Biostymin (2, 4, $8 \mu \mathrm{l})$ significantly diminished the number of newly-formed blood vessels in comparison to the control. Similar angio-inhibitory effect in TIA test was obtained by our group for another Aloe preparation, Aloe vera drinking gel $(50$ or $150 \mu \mathrm{l})$ [115].

In our next paper we desribed the results of the study performed on the basis of LIA. This is a model of local graft-versus-host $(\mathrm{GVH})$ reaction, marker of the earliest events resulting from activation of donor lymphocytes after contact with host semi-allogeneic histocompatibility antigens [99]. The effect of in vivo oral administration of Aloe vera gel ( 50 or $150 \mu \mathrm{l})$ for 21 days to maternal strain (Balb/c) donor mice on the ability of their splenic lymphocytes to induce cutaneous angiogenesis (LIA test) in F1 $\mathrm{Balb} / \mathrm{c}$ x $\mathrm{C} 3 \mathrm{H}$ recipients was studied. Our results showed that neovascular reaction evaluated $72 \mathrm{~h}$ after cells grafting was significantly lower in mice grafted with splenocytes collected from Aloe-fed donors than from the controls. The use of Aloe vera gel or its components for the treatment of a variety of conditions and diseases needs further clinical evidence through well-designed studies with defined Aloe extracts and matching placebo controls.

\section{Resveratrol}

Resveratrol (3,5,4'-trihydroxystilbene) is a natural polyphenol classified in the stilbenes group. The molecule was first detected in 1940 as a constituent of the roots of white hellebore (Veratrum grandiflorum) [116]. Two decades later resveratrol was identified in the Japanese knotweed roots (Polygonum cuspidate), used in the traditional Chinese and Japanese medicine as Hu Zhang/Ko-jo-kon [117-119] described as a new class of phytoalexins from grapevines. The term "phytoalexin" was used in this context as the synthesis of resveratrol is induced by microbial infections as the fungus Botrytis cinerea or UV radiation [120]. Currently this polyphenolic phytoalexin is found in more than 70 plant species. The source of resveratrol include the skin of red grapes, red wine, Polygonum cuspidate, peanuts and blueberries [121-122]. This natural polyphenol has received wide attention due to its possible role in the prevention of human pathologic processes, including malignancies, diabetic retinopathy, or cardiovascular diseases [122, 123]. In the 90'ies a relationship between a wine consumption and reduced cardiovascular risk was identified, which turned to be a phenomenon called as the "French Paradox". Resveratrol was widely investigated. This natural polyphenol is known for a pleiotropic mode of action [122, 124].

Several biological effects for the exerted cardioprotective action of this polyphenol have been identified including e.g. (1) reduction of platelet aggregation; (2) vasodilatation; (3) decrease of lipid peroxidation and improvement of serum cholesterol profile; (4) anti-atherosclerotic action; (5) protection of endothelial cells against apoptosis and induction of neovascularisation of the infarcted myocardium; and (6) diminishing of smooth muscle cell proliferation [124]. Many of the biological actions of resveratrol have been attributed to its antioxidant properties [125]. Park et al. [126] demonstrated that resveratrol inhibited foam cell formation, a key step in atherosclerosis process, as well as ROS production. In particular, resveratrol blocked ROS production by inhibiting the expression of NOX-1, and further inhibited monocyte chemotactic protein-1 (MCP-1) production as well. Oxidation of LDL favors the transfor- 
mation of macrophages into foam cells. This process is considered to be dependent on ROS produced via NOX. Modulating of this process by resveratrol might have potential impact on regulation of vascular endothelium microenvironment [126]. Interestingly, the ability of resveratrol (concentration-dependent between $1 \mu \mathrm{mol} / 1$ - 100 $\mu \mathrm{mol} / \mathrm{l})$ to activate the erythrocyte plasma membrane redox system and extracellular ascorbate free radicals reductase may provide protection to the plasma membrane against oxidative changes [127]. The study of Olas et al. [128] revealed that resveratrol $(1-25 \mu \mathrm{g} / \mathrm{ml})$ reduced the oxidative stress in blood platelets induced by platinum compounds as cisplatin or selenium-cisplatin conjugate $(10 \mu \mathrm{g} / \mathrm{ml})$. Resveratrol decreased platelet lipid peroxidation and ROS production caused by these compounds.

During the recent decades studies focused on potential strategies that could limit oxidation in the retina thus preventing or at least decreasing prevalence of many retinal diseases which etiology is associated with oxidative stress. King et al. [129] proved that resveratrol $(100 \mu \mathrm{mol} / \mathrm{l})$ inhibiting basal and $\mathrm{H}_{2} \mathrm{O}_{2}$-induced intracellular oxidation protected retinal pigment epithelium (RPE) cells from $\mathrm{H}_{2} \mathrm{O}_{2}$-induced cell death. Mansoor et al. [130] showed that at $30 \mu \mathrm{mol} / \mathrm{l}$, resveratrol (as genistein and as memantine) can reverse the apoptosis and oxidant production generated by benzo(e)pyrene, a toxic component of cigarette smoke. The authors suggested that these agents might have a protective effect in retinal diseases linked with the damage of RPE cells.

The team by Szaflik and Majsterek investigated the effect of resveratrol on oxidative stress based on DNA damages in lymphocytes of patients with AMD and healthy subjects. Resveratrol at $5 \mu \mathrm{mol} / \mathrm{l}-50 \mu \mathrm{mol} / \mathrm{l}$ concentrations decreased oxidative DNA lesions in lymphocytes of patients with AMD as compared to healthy controls. It was also found that resveratrol might increase the activity of main antioxidative enzymes, including glutathione peroxidase, superoxide dismutase and catalase in patient cells [131]. Recently published data support the hypothesis that resveratrol may be able to protect the retina against ischaemia by downregulation of MMP-9 and inducible NO and upregulation of heme oxygenase-1 (HO-1) [132].

The anti-angiogenic potency of resveratrol attracts attention of researchers. For the first time Brĺkenhielm et al. [133] demonstrated clearly the anti-angiogenic properties of orally administrated resveratrol. It was shown that resveratrol significantly suppressed VEGF- and FGF-2-induced corneal neovascularization in the mice model.

Hua et al. [134] showed that the oral administration of resveratrol significantly suppressed pathologic retinal neovascularisation in the very low-density lipoprotein receptor (VLDLR) mutant mouse (Vldlr -/-), which typically develops by the end of the second postnatal week. In addition, resveratrol treatment significantly reduced VEGF transcription in the retinas of Vldlr $-/-$ mice and dimin- ished VEGF-induced phosphorylation of MAPK in vitro. Other studies confirmed inhibitory concentration-dependent $(0-10 \mu \mathrm{M})$ activity of resveratrol on VEGF secretion in models of hyperglycemia-induced inflammation in RPE cells [135].

Recently, it was documented by Seong et al that resveratrol suppresses VEGF secretion via inhibition of CXCchemokine receptor 4 (CXCR4) expression in ARPE-19 cells [136].

Zhang reported the suppressive effect of resveratrol on hypoxia-inducible factor- $1 \alpha$ and VEGF expression after warm ischemia and reperfusion in rat liver [137].

Gliemann et al. tested the hypothesis that resveratrol supplementation enhances training-induced improvements in cardiovascular health parameters in aged men. Unfortunately, their results indicate that resveratrol supplementation blunted beneficial effects of exercise training [138].

It was reported that resveratrol and black tea polyphenol combination synergistically suppress mouse skin tumors groth by inhibition of activated MAPKs and p53 [139].

Recently, Lee et al. [140] described experiments performed in a B16 murine melanoma model. Their results suggest that co-treatment with resveratrol and 5-fluorouracil suppressed cell growth and angiogenesis in these tumors.

\section{Plumbagin}

Plumbagin is an antioxidant belonging to NOX inhibitors, isolated from the root of the medicinal plant Plumbago zeylanica L. (Plumbaginaceae). It is a naphthoquinone, which exerts antiatherosclerotic and anticarcinogenic effects in both in vivo and in vitro models. Plumbagin was shown to inhibit NADPH-dependent superoxide production in cell lines, that express NOX4 oxidase [141]. Its anticancer activity was demonstrated in osteosarcoma cells, and human non-small cell lung cancer cell lines [142], ovarian cancer cells [143], as well as prostate cancer cells [144]. Plumbagin-induced inhibition of prostate cancer cell growth and invasion accompanied inhibition of protein kinase $\mathrm{C} \varepsilon(\mathrm{PKC} \varepsilon)$ and transcription factors AP-1, $\mathrm{NF}-\kappa \mathrm{B}$, and phosphorylated signal transducer and activator of transcription (Stat3). In ovarian cancer cells, plumbagin was reported to block p53 expression and its negative regulator, Mdm2. Furthermore, this compound was able to supress VEGF and Glut-1 expression in EC and in ovarian cancer cells. It was also shown that plumbagin activated ERK1/2 signaling pahway via ROS in ovarian cancer cells. The mode of action of plumbagin on endothelial cells and ovarian cancer cells was shown to be different. It inhibited MAPK-42/44 phosphorylation, induced p53 in EC, induced MAPK-42/44 phosphorylation and inhibited p53 in ovarian cancer cells [143]. Proliferation of human nonsmall cell lung cancer cell lines was dose-dependently inhibited by plumbagin in Xu et al. [142] study. The group 
revealed that this compound induced apoptosis in these cells lines via NFKB-regulated mitochondrial-mediated pathway involving ROS activation. Plumbagin anticancer activity was also demonstrated in vivo. The substance was able to stop vessel formation in ovarian tumors and inhibit tumor angiogenesis [143, 145].

\section{Antioxidants supplements}

\section{PADMA 28}

Among many natural substances used for years in the treatment of human diseases PADMA 28, a herbal multi-compound remedy, has the roots in old Tibetan medicine [146]. It is a medicinal product produced in Switzerland (PADMA AG company). The preparation is known to exert angioprotecive, antioxidative and wound-healing properties. Bioflavonoids, tannins, phenolic acids, phenolic alcohols, and terpenoids were determined as the principal PADMA's active compounds [147, 148]. In humans, PADMA 28 has been used as a tonic for heart and blood vessels and as an antioxidant. This remedy was registered in Switzerland in 1977, as a substance relieving symptoms of claudication, handicapped peripheral blood circulation, leg spasms, and neuropathy [149].

There are some research papers about PADMA 28 anti-cancer activity; it inhibits cancer prostate cell migration [150], and has anti-angiogenic properties by suppressing angiogenesis in vitro and in vivo through AKT/GSK- $3 \beta$ pathways [151].

Padma 28 seems to be a possible candidate for the care in diseases such as Alzheimer's disease (AD) and other CNS diseases [152].

Our group performed a series of experiments with different plant remedies (PADMA 28, Immunal (extract of E. Purpurea), Reumaherb (see below) and Bioaron C) displaying immunostimulatory properties. The topic of the first one was to exclude the possible unwanted stimulatory consequence of these remedies on the early steps of tumor angiogenesis. Additionally, we wanted to select remedies with both immune-stimulatory and angio-inhibitory properties, for use as a safe adjunctive treatment in immuno-compromised patients with cancers. Examined substances were given to mice orally in daily doses recalculated from the doses recommended for humans. All tested remedies decreased skin angiogenesis stimulated by human kidney cancer homogenate. The highest inhibitory effect was presented by Immunal $(0.64 \mathrm{mg})$ and by PADMA $28(5.8 \mathrm{mg})$ [153]. Important finding is that no stimulation of neovascular reaction was observed in all experimental groups. This opens the possibility for safe use of all presented herbal remedies in patients with cancers, or with high risk of cancer, for improving their immunity. In the next study we checked the in vivo effect of PADMA 28 on the in vitro mitogen - stimulated proliferation of murine splenic lymphocytes and their chemokinetic activity in cell culture. No differences were observed among examined groups, fed with different PADMA daily doses $5.8 \mathrm{mg}$ or $0.085 \mathrm{mg}$ ). In experimental groups, the reaction of splenic lymphocytes to PHA and their in vitro chemokinetic action was significantly raised as compared to the controls. This shows that PADMA 28 stimulated cell-mediated immunity in examined animals and might be used as immuno-modulating substance in the wide spectrum of doses [146]. In the last experiment we checked the influence of PADMA administered in high and low daily doses $(5.8 \mathrm{mg}$ or $0.085 \mathrm{mg}$ ), on immunological angiogenesis and granulocyte metabolic activity in Balb/c mice. We observed strong significant angiogenic response in ex vivo test after transplantation of Balb/c splenocytes from both examined dosage groups; increase of blood lymphocytes and granulocyte number only in mice fed with lower dose of remedy; and diminishing of respiratory burst of blood granulocytes in animals fed with higher dose of PADMA (antioxidant effect). It seems that PADMA28 may accelerate physiological angiogenesis in lower doses, and behave as a good antioxidant in higher doses [149].

Summarizing, Padma 28 displays characteristics of angiogenesis modulator. It diminishes high level of cancer cell- induced neovascularisation and increases physiological angiogenesis. It allows applying this preparation in wide spectrum of angiogenesis-related diseases.

\section{Resvega}

Resvega is the product containing $2 \%$ of Resveratrol apart antioxidant vitamins (Vit C, Vit E), trace elements (Zinc, Copper), Omega 3 essential fatty acids, lutein and zeaxanthin (Laboratoires Thea). The study by Recalde et al. [154], showed that Resvega can prevent the choroidal neovascularisation-induced lesions as well as can prevent VEGF expression increase in the animal model. Lançon et al. [155] presented that two pro-inflammatory cytokines IL- 6 and IL- 8 were down-regulated by resveratrol and Resvega treatments by at least $50-60 \%$ in all conditions, even at the very low concentrations $(1 \mu \mathrm{M})$. The investigators demonstrated also a dose-dependent (10-50 $\mu \mathrm{M}$ ) inhibition of VEGF-A levels by resveratrol and by Resvega in in vitro model on human retinal pigment epithelium cell line ARPE-19 (Lançon et al., 2012). Another report showed the dose-dependent (in the range of 25-100 $\mu \mathrm{M})$ anti-angiogenic effect of resveratrol and Resvega on RF/6A retinal endothelial cells [156]. The increasing number of evidence suggests the potential interest to use resveratrol-containing products in new therapeutic area in the clinical ophthalmological practice, to modulate the processes connected with ocular choroidal neovascularisation.

\section{Reumaherb}

Reumaherb preparation (Herbapol, Poland) contains extracts of three herbs: Echinacea purpurea, Filipindula ulmaria and Harpagophytum procumbens (Hp). 
E. purpurea, as was mentioned before, is known for their anti-viral, anti-inflammatory and immunomodulatory properties. It has also antioxidative and antiangiogenic activities. This herb is broadly applied for the treatment of upper respiratory tract infections. Immune activity of E. purpurea is based on enhancing antibody production, phagocytosis, cellular respiratory activity and lymphocyte activation as well as release of various anti-inflammatory cytokines.

F. ulmaria (Rosaceae) known as a meadowsweet herb of northern and southern Europe, North America, and Northern Asia, is commonly used due to its anti-inflammatory, immunoregulatory and antioxidative properties. Flavone glycoside (spiraeoside) ensures antioxidant activity present in flowers of $F$. ulmaria. Its hepatoprotective properties have been also shown. It is widely applicated in therapy of common cold, influenza, and inflammatory conditions such as osteoarthritis and rheumatoid arthritis [157].

H. procumbens (Pedaliaceae) colloqially named Devil's clow is herbal remedy, originated from traditional South African medicine, used for rheumatic disorders. Analgesic and anti-inflammatory properties of $H$. procumbens allow to use it as supportive herbal medicine in treatment of pains of various origin and degenerative joint diseases in European countries. In clinical trials, H. procumbens was succesfully used for alleviation of pain and improvement of mobility in a variety of musculoskeletal disorders [158].

Nowadays, Reumaherb preparation is applied as a supportive herbal medicine in treatment of inflammatory and degenerative disorders of joints e.g. RA and various muscoskeletal conditions [153,159].

Results of experiments of our group have shown that Reumaherb applied orally to mice (daily doses $1.2 \mathrm{mg}$ per mice, calculated from the doses recommended for humans) exerted anti-inflammatory and anti-angiogenic action on mononuclear cells derived from RA patients. Furhermore, the similar effect of Reumaherb on bronchoalveolar lavage cells (BAL) from sarcoidosis patients was observed. RA and sarcoidosis belong to the group of diseases with high level of angiogenesis. Rheumaherb, by diminishing neovascular response, seems to be a promising preparation in this group of diseases [160]. This herbal preparation (1.2 $\mathrm{mg} /$ day/mice) inhibited also tumour angiogenesis induced by kidney clear cell carcinoma homogenate in mice. This confirms its anti-angiogenic activity [159] and encourages to further investigation testing if it is possible to use it in neoplastic diseases.

\section{Conclusions}

Most antioxidants described in this review negatively regulate angiogenesis. This kind of action seems to be a general rule for antioxidants, but further studies are needed. The exceptions are: 1 . angiomodulatory effects of Rhodiola and 2. PADMA 28 preparation which presented angioregulatory activity, decreasing high angiogenesis of cancer cells and increasing physiological angiogenesis. This kind of antioxidant can be safely used in therapy of patients with various disturbances of angiogenesis or oxidant balance, including patients with low level angiogenesis diseases. For patients with abnormally high angiogenesis, most of known antioxidants will be curable. Particular attention should be paid also to proper dose of antioxidant treatment, because too high levels of these substances can provoke oxidative effect that can induce development of oxidant related disease.

The authors declare no conflict of interest.

This work was supported by grant of the National Centre of Science 2012/05/B/NZ 7/03219.

\section{References}

1. Devasagayam TPA, Tilak JC, Boloor KK, et al. (2004): Free radicals and antioxidant in human health: current status and future prospects. JAPI 52: 794-804.

2. Brambilla D, Mancuso C, Scuderi MR, et al. (2008): The role of antioxidant supplement in immune system, neoplastic, and neurodegenerative disorders: a point of view for an assessment of the risk/benefit profile. Nutr J 30: 7-29.

3. Manea A (2010): NADPH oxidase-derived reactive oxygen species: involvement in vascular physiology and pathology. Cell Tissue Res 342: 325-339.

4. Carmeliet P, Jain RK (2011): Molecular mechanisms and clinical applications of angiogenesis. Nature 473 (7347): 298 $-307$.

5. Skopiński P, Szaflik J, Duda-Król B, et al. (2004): Suppression of angiogenic activity of sera from diabetic patients with non-proliferative retinopathy by compounds of herbal origin and sulindac sulfone. Int J Mol Med 14(4): 707-11.

6. Fong GH (2008): Mechanism of adaptive angiogenesis and tissue hypoxia. Angiogenesis 11:121-140.

7. Rankin EB, Giaccia AJ (2008): The role of hypoxia-inducible factors in tumorigenesis. Cell Death Differ 15: 678-685.

8. Chorostowska-Wynimko J, Kędzior M, Struniawski R, et al. (2010): Differential regulation of TNF alpha and TGF beta production by the PAI-1 in endothelial and cancer cells. Cetr Eur J Immunol 35: 123-127.

9. Bellon G, Martiny L, Robinet A (2004): Matrix metalloproteinases and matrikines in angiogenesis. Crit Rev Oncol Hematol 49: 203-220.

10. Nijmeh J, Moldobaeva A, Wagner EM (2010): Role of ROS in ischemia-induced lung angiogenesis. Am J Physiol Lung Cell Mol Physiol 299 (4): L535-41.

11. Łuczak K, Balcerczyk A, Soszyński M, Bartosz G (2004): Low concentration of oxidant and nitric oxide donors stimulate proliferation of human endothelial cells in vitro. Cell Biol Int 28 (6): 483-486.

12. Maloney E, Sweet IR, Hockenbery DM, et al. (2009): Activation of NFkappa B by palmitate in endothelial cells: a key role for NADPH oxidase-derived superoxide in response to TLR4 activation. Arterioscler Thromb Vasc Biol 29: 1370-1375. 
13. Nakayama A, Alladin KP, Igbokwe O, White JD (2011): Systematic review: generating evidence-based guidelines on the concurrent use of dietary antioxidants and chemotherapy or radiotherapy. Cancer Investigat 29: 655-667.

14. Ushio-Fukai M, Tang Y, Fukai T, et al. (2002): Novel role of gp91 phox-containing $\mathrm{NAD}(\mathrm{P}) \mathrm{H}$ oxidase in vascular endothelial growth factor-induced signaling and angiogenesis. Circ Res 91: 1160-1167.

15. Diebold I, Petry A, Hess J, Görlach A (2010): The NADPH oxidase subunit NOX4 is a new target gene of the hypoxia-inducible factor-1. Mol Biol Cell 10: 2087-2096.

16. Soares H, Marinho HS, Real C, Antunes F (2014): Cellular polarity in aging: role of redox regulation and nutrition. Genes Nutr 9: 1-17.

17. Stone JR, Collins T (2002): The role of hydrogen peroxide in endothelial proliferative responses. Endothelium 9: 231-238.

18. Shono T, Ono M, Izumi H, Jimi SI, et al. (1996): Involvement of the transcription factor NF-kappa B in tubular morphogenesis of human microvascular endothelial cells by oxidative stress. Mol Cell Biol 16: 4231-4239.

19. Kim YM, Kim KE, Koh GY (2006): Hydrogen peroxide produced by angiopoietin-1 mediates angiogenesis. Cancer Res 66: 6167-6174.

20. Kim HW, Lin A, Guldberg RE (2007): Essential role of extracellular SOD in reparative neovascularization induced by hindlimb ischemia. Circ Res 101 Supp 4: 409-419.

21. Goyal P, Weissmann N, Grimminger F, et al. (2004): Upregulation of $\mathrm{NAD}(\mathrm{P}) \mathrm{H}$ oxidase 1 in hypoxia activates hypoxia-inducible factor 1 via increase in reactive oxygen species. Free Radic Biol Med 36: 1279-1288.

22. Bouayed J, Bohn T (2010): Exogenous antioxidants - double-edged swords in cellular redox state: health beneficial effects at physiologic doses versus deleterious effects at high doses. Oxid Med Cell Longev 3: 228-237.

23. Pokorny J (2007): Are natural antioxidants better - and safer - than synthetic antioxidants? Eur J Lipid Sci Technol 109: 629-642.

24. Lawenda BD, Kelly KM, Ladas EJ, et al. (2008): Should supplemental antioxidant administration be avoided during chemotherapy and radiation therapy? J Natl Cancer Inst 100: 773-783.

25. Jerome-Morais A, Diamond AM, Wright ME (2011): Dietary supplements and human health: for better or for worse? Mol Nutr Food Res 55: 122-135.

26. Goodman M, Bostick RM, Kucuk O, Jones DP (2011): Clinical trials of antioxidants as cancer prevention agents: past, present, and future. Free Radic Biol Med 51: 1068-1084.

27. Chan JY, Yuen ACh, Chan R, Chan SW, et al. (2013): A review of the cardiovascular benefits and antioxidant properties of allicin. Phytother Res 27: 637-646.

28. Chun OK, Floegel A, Chung SJ, Chung ChE, et al. (2010): Estimation of antioxidant intakes from diet and supplements in U.S. adults. J Nutr 140: 317-324.

29. Sarna LK, Wu N, Hwang SY, Siow YL (2010): Berberine inhibits NADPH oxidase mediated superoxide anion production in macrophages. Can J Physiol Pharmacol 88: 369-78.

30. Heo SK, Yun HJ, Noh EK, Park SD (2010): Emodin and rhein inhibit LIGHT-induced monocytes migration by blocking of ROS production. Vascul Pharmacol 53: 28-37.

31. Lee WJ, Ou HC, Hsu WC (2010): Ellagic acid inhibits oxidized LDL-mediated LOX-1 expression, ROS generation, and inflammation in human endothelial cells. J Vasc Surg 52: 1290-300.
32. Guzik TJ, Sadowski J, Guzik B, et al. (2006): Coronary artery superoxide production and Nox isoform expression in human coronary artery disease. Arterioscler Thromb Vasc Biol 26: 333-339.

33. Furmanowa M, Skopińska-Różewska E, Rogala E, Hartwich M (1998): Rhodiola rosea in vitro culture-phytochemical analysis and antioxidant action. Acta Societ Botanic Pol 67: 69-73.

34. Spasov AA, Wikman GK, Mandrikov VB, et al. (2000): A double-blind, placebo-controlled pilot study of the stimulating and adaptogenic effect of Rhodiola rosea SHR-5 extract on the fatigue of students caused by stress during an examination period with a repeated low-dose regimen. Phytomed 7: 85-89.

35. Darbinyan V, Kteyan A, Panossian A, et al. (2000): Rhodiola rosea in stress induced fatigue - a double blind cross-over study of standardized extract SHR-5 with repeated low dose regimen on the mental performance of healthy physicians during night duty. Phytomed 7: 365-370.

36. Krajewska-Patan A, Gryszczyńska A, Mielcarek S, et al. (2013): Możliwości wykorzystania różeńca Kiryłowa (Rhodiola kirilowii) w nowoczesnej fitoterapii. Postępy Fitoterapii 1: 22-27.

37. Udintsev SN, Shakhov VP (1991): The role of humoral factors of regenerating liver in the development of experimental tumors and the effect of Rhodiola rosea extract on this process. Neoplasma 38: 323-331.

38. Maslov LN, Lishmanov YB, Maimessulova LA, Krashov EA (1998): A mechanism of antiarrhythmic effect of Rhodiola rosea. Bull Exp Biol Med 125: 374-376.

39. Maslov LN, Lishmanov YB, Naumova AV, Lasukova TV (1997): Do endogenous ligands of peripheral $\mu$ - and $\Omega$ - opiate receptors mediate antiarrhythmic and cardioprotective effects of Rhodiola rosea. Bull Exp Biol Med 124: 754-756.

40. Li J, Fan WH, Ao H (2005): Effect of rhodiola on expressions of Flt-1, KDR and Tie-2 in rats with ischemic myocardium. Zhongguo Zhong Xi Yi Jie He Za Zhi 25: 445-448.

41. Salikhova RA, Aleksandrova IV, Mazurik VK, et al. (1997): Effect of Rhodiola rosea on the yield of mutation alterations and DNA repair in bone marrow cells. Patol Fiziol Eksp Ter 4: $22-24$.

42. Molokovskii DS, Davydov VV, Tiulenev VV (1989): The action of adaptogenic plant preparations in experimental alloxan diabetes. Probl Endokrinol (Mosk) 35: 82-87.

43. Kwon YI, Jang HD, Shetty K (2006): Evaluation of Rhodiola crenulata and Rhodiola rosea for management of type II diabetes and hypertension. Asia Pac J Clin Nutr 15: 425-432.

44. Niu CS, Chen LJ, Niu HS (2014): Antihyperglycemic action of Rhodiola - aqueous extract in type-1-like diabetic rats. BMC Complement Altern Med 14: 20.

45. Wolski T, Baj T, Ludwiczuk A (2008): Rodzaj Rhodiola systematyka, skład chemiczny, działanie i zastosowanie oraz analiza fitochemiczna korzeni dwu gatunków różeńca: Rhodiola rosea L.oraz Rhodiola quadrifida (Pall.) Fish et Mev. Postępy Fitoterapii 1: 2-14.

46. Boldsaikhan B (2004): Encyclopedia of Mongolian Medicinal Plants. Mongolian University of Science and Technology, Ulaanbaatar.

47. Wiedenfeld H, Dumaa M, Malinowski M, et al. (2007): Phytochemical and analytical studies of extracts from Rhodiola rosea and Rhodiola quadrifida. Pharmazie, 62: 308-311.

48. Peng JN, Ma CY, Ge YC (1994): Chemical constituents of Rhodiola kirilowii (Regel). Zhongguo Zhong Yao Za Zhi 19: 676-702. 
49. Grace MH, Yousef GG, Kurmukov AG, et al. (2009): Phytochemical characterization of an adaptogenic preparation from Rhodiola heterodonta. Nat Prod Commun 4 (8): 1053-1058.

50. Grech-Baran M, Sykłowska-Baranek K, Krajewska-Patan A, et al. (2014): Biotransformation of cinnamyl alcohol to rosavins by non-transformed wild type and hairy root cultures of Rhodiola kirilowii. Biotechnol Lett 36: 649-656.

51. Raj K, Kumar Ph G, Chaurasia OP (2010): In vitro antioxidant activity of methanolic extract of Rhodiola Imbricata Edgew. Pharmacog J 2:157-161.

52. Born M, Carrupt PA, Zini R, et al. (1996): Electrochemical behavior and antioxidant activity of some natural polyphenols. Helvet Chim Acta 79: 1147-1158.

53. Yuan Y, Wu SJ, Liu X, Zhang LL (2013): Antioxidant effect of salidroside and its protective effect against furan-induced hepatocyte damage in mice. Food Funct 4 (5): 763-769.

54. Qu ZeQ, Zhou Y, Zeng YS, et al. (2012): Protective Effects of a Rhodiola Crenulata Extract and Salidroside on Hippocampal Neurogenesis against Streptozotocin-Induced Neural Injury in the Rat. PLOS One 7: e29641.

55. Covas M, Miro-Cavas E, Fito M, et al. (2003): Bioavailability of tyrosol, an antioxidant phenolic compound present in wine and olive oil, in humans. Drugs Exp Clin Res 29: 203-206.

56. Vlachogianni IC, Fragopoulou E, Kostakis I, et al. (2015): In vitro assessment of antioxidant activity of tyrosol, resveratrol and their acetylated derivatives. Food Chemistry 177: 165173.

57. Whang WK, Park HS, Ham IH, et al. (2005): Methyl gallate and chemicals structurally related to methyl gallate protect human umbilical vein endothelial cells from oxidative stress. Exp Mol Med 37: 343-352.

58. Serrano J, Cipak A, Boada J, et al. (2010): Double-edged sword behavior of gallic acid and its interaction with peroxidases in human microvascular endothelial cell culture (HMEC-1). Antioxidant and prooxidant effects. Acta Biochim Pol 57: 193-198.

59. Kanupriya M, Prasad D, Sai RM, et al. (2005): Cytoprotective and antioxidant activity of Rhodiola imbricata against tert-butyl hydroperoxide induced oxidative injury in U-937 human macrophages. Mol Cell Biochem 275: 1-6.

60. Jaiswal N, Rizvi SI (2014): Onion extract (Allium cepa L.), quercetin and catechin up-regulate paraoxonase 1 activity with concomitant protection against low-density lipoprotein oxidation in male Wistar rats subjected to oxidative stress. J Sci Food Agric 94: 2752-2757.

61. Ji J, Lin Y, Huang SS, et al. (2013): Quercetin: a potential natural drug for adjuvant treatment of RA. Afr J Tradit Complement Altern Med 10: 418-421.

62. Kędzia B, Furmanowa M, Krajewska-Patan A, et al. (2006): Badania toksykologiczne, farmakologiczne, i mikrobiologiczne wyciągów z kłączy Rhodiola rosea, R. kirilowii i R. quadrifida. Herba Polonica 52: 105-106.

63. Okulicz-Kozaryn I, Mikołajczak PŁ, Siekierkowska A, et al. (2006): Ocena działania przeciwzapalnego wyciągów z Rhodiola kirilowii (Regel) Maxim i Rhodiola rosea L. Herba Polonica 52: 56-57.

64. Siwicki AK, Skopinska-Różewska E, Hartwich M, et al. (2007): The influence of Rhodiola rosea extracts on non-specific and specific cellular immunity in pigs, rats and mice. Centr Eur J Immunol 32: 84-91.

65. Skopinska-Różewska E, Wójcik R, Siwicki AK, et al. (2008): The effect of Rhodiola quadrifida extracts on cellular immunity in mice and rats. Pol J Vet Sci 11: 105-111.
66. Wójcik R, Siwicki AK, Skopińska-Różewska E, et al. (2009):The effect of chinese medicinal herb Rhodiola kirilowii extracts on cellular immunity in mice and rats. Pol J Vet Sci 12: 399-404.

67. Wójcik R, Siwicki AK, Skopinska-Różewska E, et al. (2008): The in vitro influence of Rhodiola quadrifida extracts on non-specific cellular immunity in pigs. Centr Eur J Immunol 33: $105-108$.

68. Skopińska-Różewska E, Sokolnicka I, Siwicki AK, et al. (2011): Dose-dependent in vivo effect of Rhodiola and Echinacea on the mitogen-induced lymphocyte proliferation in mice. Pol J Vet Sci 14: 265-272.

69. Skopińska-Różewska E, Bychawska M, Białas-Chromiec B, et al. (2010): The in vivo effect of Rhodiola kirilowii extracts on blood granulocytes metabolic activity in mice. Centr Eur J Immunol 35: 20-24.

70. Bany J, Zdanowska D, Skopinska-Różewska E, et al. (2009): The effect of Rhodiola rosea extracts on the bacterial infection in mice. Centr Eur J Immunol 34: 35-37.

71. Skopinska-Różewska E, Bychawska M, Białas-Chromiec B, Sommer E (2009): The in vivo effect of R.rosea and R. quadrifida hydro-alcoholic extracts on chemokinetic activity of spleen lymphocytes in mice. Centr Eur J Immunol 34: 42-45.

72. Wójcik R, Siwicki AK, Skopińska-Różewska E, et al. (2009): The in vitro influence of R.kirilowii extracts on blood granulocytes potential killing activity (PKA) in pigs. Centr Eur J Immunol 34: 158-161.

73. Wójcik R, Siwicki AK, Skopinska-Różewska E, et al. (2009): The in vitro effect of R.quadrifida and R. kirilowii extracts on pigs blood lymphocyte response to mitogen ConA. Centr Eur J Immunol 34: 166-170.

74. Skopińska-Różewska E, Bychawska M, Sommer E, Siwicki AK (2008): The in vivo effect of Rhodiola quadrifida extracts on the metabolic activity of blood granulocytes in mice. Centr Eur J Immunol 33: 179-181.

75. Siwicki AK, Skopińska-Różewska E, Wasiutyński A, et al. (2012): The effect of Rhodiola kirilowii extracts on pigs blood leukocytes metabolic (RBA) and proliferative (LPS) activity, and on the bacterial infection and blood leukocyte number in mice. Centr Eur J Immunol 37: 145-150.

76. Skopińska- Różewska E, Stankiewicz W, Zdanowski R, et al. (2012): The in vivo effect of Rhodiola quadrifida extracts on the antibody production, blood leukocytes subpopulations and on the bacterial infection in mice. Centr Eur J Immunol 37: 140-144.

77. Zdanowski R, Lewicki S, Skopińska-Różewska E, et al. (2014): Alcohol- and water-based extracts obtained from Rhodiola rosea affect differently the number and metabolic activity of circulating granulocytes in Balb/c mice. Ann Agric Environ Med 21: 120-123

78. Hartwich M (2010): The importance of immunological studies on Rhodiola rosea in the new effective and safe herbal drug discovery. Centr Eur J Immunol 35: 263-266.

79. Skopińska-Różewska E, Wasiutyński A, Sommer E, et al. (2008): The influence of Rhodiola rosea, R.kirilowii, and R.quadrifida extracts on cutaneous angiogenesis induced in mice after grafting of human kidney cancer tissue. Centr Eur J Immunol 33: 185-189.

80. Skopińska-Różewska E, Hartwich M, Siwicki AK, et al. (2008): The influence of R.rosea extracts and rosavin on cutaneous angiogenesis induced in mice after grafting of syngeneic tumor cells. Centr Eur J Immunol 33: 102-107. 
81. Skopinska-Różewska E, Mścisz A, Sommer E, et al. (2005): The influence of different Rhodiola extracts on murine tumor cells angiogenic activity. Herba Pol 51 (S1): 172.

82. Skopińska-Różewska E, Malinowski M, Wasiutyński A, et al. (2008): The influence of R. quadrifida $50 \%$ hydro-alcoholic extract and salidroside on tumor-induced angiogenesis in mice. Pol J Vet Sci 11: 97-104.

83. Zdanowski R, Skopińska-Różewska E, Wasiutyński A, et al. (2012): The effect of Rhodiola kirilowii extracts on tumor-induced angiogenesis in mice. Centr Eur J Immunol 37: 131-139.

84. Polytarchou C, Papadimitriou E (2004): Antioxidants inhibit angiogenesis in vivo through down-regulation of nitric oxide synthase expression and activity. Free Radic Res 38: 501-508.

85. Belotti D, Vergani V, Drudis T, et al. (1996): The microtubule - affecting drug paclitaxel has antiangiogenic activity. Clin Cancer Res 2: 1843-1849.

86. Prochazkova D, Bousova I, Wilhelmova N (2011): Antioxidant and prooxidant properties of flavonoids. Fitoterapia 82 : 513-53.

87. Rice-Evans CA, Miller NJ, Paganga G (1997): Antioxidant properties of phenolic compounds. Trends Plant Sci 2: 152159.

88. Bałan B, Różewski F, Zdanowski R, Skopińska-Różewska E. (2012a). Immunotropic activity of Echinacea. Part I. History and chemical structure. Centr Eur J Immunol 7: 45-50.

89. Bałan B, Różewski F, Skopińska-Różewska E, et al. (2012): Immunotropic activity of Echinacea. Part II. Experimental and clinical data. Centr Eur J Immunol 37: 51-56.

90. Bany J, Siwicki AK, Zdanowska D, et al. (2003): Echinacea purpurea stimulates cellular immunity and anti- bacterial defence independently of the strain of mice. Pol J Vet Sci 6 (suppl 3): 3-5.

91. Rogala E, Skopińska-Różewska E, Wasiutyński A, et al. (2008): Echinacea purpurea diminishes neovascular reaction induced in mice skin by human cancer cells and stimulates non-specific cellular immunity in humans. Centr Eur J Immunol 33: 127-130.

92. Wasiutyński A, Bałan B, Skopińska-Różewska E, et al. (2009): The effect of Echinacea purpurea on the morphology, angiogenic activity and vascular endothelial growth factor (VEGF) concentration of murine L-1 sarcoma tumors. Centr Eur J Immunol 34: 38-41.

93. Skopińska-Różewska E, Sommer E, Bałan B, et al. (2010): The in vivo effect of dry hydro-alcoholic extract of Echinacea purpurea on angiogenic activity of human blood mononuclear cells. Centr Eur J Immunol 35: 223-226.

94. Skopińska-Różewska E, Sokolnicka I, Siwicki AK, et al. (2011): Dose-dependent in vivo effect of Rhodiola and Echinacea on the mitogen-induced lymphocyte proliferation in mice. Pol J Vet Sci 14: 265-272.

95. Bałan BJ, Słotwiński R, Skopińska-Różewska E (2009): Role of angiogenesis and angiogenic factors in colorectal cancer. Centr Eur J Immunol 34: 254-260.
96. Barcz E, Sommer E, Nartowska J, et al. (2007): Influence of Echinacea purpurea intake during pregnancy on fetal growth and tissue angiogenic activity. Folia Histochem Cytobiol 45: 35-39.

97. Gallo M, Sarkar M, Au W, et al. (2000): Pregnancy outcome following gestational exposure to Echinacea. Arch Intern Med 160: 3141-3143.

98. Grundmann O (2012): Aloe vera gel research review. An overview of its clinical uses and proposed mechanisms of action. Natur Medic J 4 (ISSN 2157-6769).

99. Skopiński P, Lewicki S, Bałan BJ, et al. (2014): In vivo inhibitory effect of Aloe vera gel on the ability of mouse parental splenic lymphocytes to induce cutaneous angiogenesis in recipient F1 mice. Pol J Vet Sci 17: 131-136.

100. Lans CA (2006): Ethnomedicines used in Trinidad and Tobago for urinary problems and diabetes mellitus. J Ethnobiol Ethnomed 2: 45.

101. Langmead L, Makins RJ, Rampton DS (2004): Anti-inflammatory effects of Aloe vera gel in human colorectal mucosa. Aliment Pharmacol Ther 19: 521-527.

102. Vaidya A, Devasagayam T (2007): Current status of herbal drugs in India: An overview. J Clin Biochem Nutr 41: 1-11.

103. Modak M, Dixit P, Londhe J, et al. (2007): Indian herbs and herbal drugs used for the treatment of diabetes. J Clin Biochem Nutr 40: 163-173.

104. Ramamoorthy L, Kemp M, Tizard I (1996): Acemannan, a beta-(1,4)-acetylated mannan, induces nitric oxide production in macrophage cell line RAW 264.7. Mol Pharmacol 50: 878-884.

105. Peng SY, Norman J, Curtin G, et al. (1991): Decreased mortality of Norman murine sarcoma in mice treated with the immunomodulator, Acemannan. Mol Biother 3: 79-87.

106. Loizou S, Lekakis I, Moutsatsou P (2010): Beta-sitosterol exhibits anti-inflammatory activity in human aortic endothelial cells. Mol Nutr Food Res 54: 551-558.

107. Lee MJ, Lee OH, Yoon SH, et al. (1998): In vitro angiogenic activity of Aloe vera gel on calf pulmonary artery endothelial (CPAE) cells. Arch Pharm Res 21: 260-265.

108. Maenthaisong R, Chaiyakunapruk N, Niruntraporn S, Kongkaew C (2007): The efficacy of Aloe vera used for burn wound healing: a systematic review. Pharmacy Practice Unit 6: 713-718.

109. Parihar MS, Chaudhary M, Shetty R, Hemnani T (2004): Susceptibility of hippocampus and cerebral cortex to oxidative damage in streptozotocin treated mice: prevention by extracts of Withania somnifera and Aloe vera. J Clin Neurosci 11: 397-402.

110. Can A, Akev N, Ozsoy N, et al. (2004): Effect of Aloe vera leaf gel and pulp extracts on the liver in type-II diabetic rat models. Biol Pharm Bull 27: 694-698.

111. Agarwal OP (1985): Prevention of atheromatous heart disease. Angiology 36: 485-492.

112. Skopińska-Różewska E, Wasiutyński A, Skopiński P (2011): In vivo effect of two complex herbal remedies Echinasal and Bioaron $\mathrm{C}$ on antibody production and immunological angiogenesis in mice. Centr Eur J Immunol 36: 139-144.

113. Bałan B, Niemcewicz M, Kocik J, et al. (2014): Oral administration of Aloe vera gel, anti-microbial and anti-inflammatory herbal remedy, stimulates cell-mediated immunity and antibody production in a mouse model. Centr Eur J Immunol 39: 14-18.

114. Skopiński P, Zdanowski R, Bałan B, et al. (2013a): Aloe arborescens and American cranberry (Vaccinium macrocar- 
pon) extracts inhibit tumor-induced cutaneous angiogenesis in mice. Centr Eur J Immunol 38: 480-485.

115. Kocik J, Bałan BJ, Zdanowski R, et al. (2014). Feeding mice with Aloe vera gel diminishes L-1 sarcoma - induced early neovascular response and tumor growth. Centr Eur J Immunol 39: 14-18.

116. Takaoka M (1940): Phenolic substances of white hellebore (Veratrum grandiflorum Loes fil.). Proc Imperial Acad (Tokyo) 16: 405-407.

117. Nonomura S, Kanagawa H, Makimoto A (1963): Chemical constituents of polygonaceous plants. I. Studies on the components of Ko-jo-kon. (Polygonum Cuspidatum Sieb.et Zucc.). Yakugaku Zasshi 83: 988-990.

118. Arichi H, Kimura Y, Okuda H, et al. (1982): Effects of stilbene components of the roots of Polygonum cuspidatum Sieb. et Zucc. on lipid metabolism. Chem Pharm Bull (Tokyo) 30: 1766-1770.

119. Langcake P, Pryce RJ (1977): A new class of phytoalexins from grapevines. Experientia 33: 151-152.

120. Liswidowati B, Melchior F, Hohmann F, et al. (1991): Induction of stilbene synthase by Botrytis cinerea in cultured grapevine cells. Planta 183: 307-314.

121. Burns J, Yokota T, Ashihara H, et al. (2002): Plant foods and herbal sources of resveratrol. J Agric Food Chem 50: 3337-3340.

122. Harikumar KB, Aggarwal BB (2008): Resveratrol: a multitargeted agent for age-associated chronic diseases. Cell Cycle 7: 1020-1035.

123. Pace-Asciak CR, Hahn S, Diamandis EP, et al. (1995): The red wine phenolics trans-resveratrol and quercetin block human platelet aggregation and eicosanoid synthesis: implications for protection against coronary heart disease. Clin Chim Acta 235: 207-219.

124. Borriello A, Cucciolla V, Della Ragione F, Galletti P (2010): Dietary polyphenols: focus on resveratrol, a promising agent in the prevention of cardiovascular diseases and control of glucose homeostasis. Nutr Metab Cardiovasc Dis 20: 618625 .

125. Hung LM, Chen JK, Huang SS, et al. (2010): Cardioprotective effect of resveratrol, a natural antioxidant derived from grapes. Cardiovasc Res 47: 549-555.

126. Park DW, Baek K, Kim JR, et al. (2009): Resveratrol inhibits foam cell formation via NADPH oxidase 1- mediated reactive oxygen species and monocyte chemotactic protein-1. Exp Mol Med 41: 171-179.

127. Rizvi SI, Pandey KB (2010): Activation of the erythrocyte plasma membrane redox system by resveratrol: a possible mechanism for antioxidant properties. Pharmacol Rep 62: 726-732.

128. Olas B, Wachowicz B (2004): Resveratrol reduces oxidative stress induced by platinum compounds in blood platelets. Gen Physiol Biophys 23: 315-326.

129. King RE, Kent KD, Bomser JA (2005): Resveratrol reduces oxidation and proliferation of human retinal pigment epithelial cells via extracellular signal-regulated kinase inhibition. Chem Biol Interact 151: 143-149.

130. Mansoor S, Gupta N, Patil AJ, et al. (2005): Inhibition of apoptosis in human retinal pigment epithelial cells treated with benzo(e)pyrene, a toxic component of cigarette smoke. Invest Ophthalmol Vis Sci 51: 2601-2607.

131. Szaflik JP, Stańczyk M, Skłodowska A, et al. (2013): Resveratrol may reduce oxidative stress in AMD patients.
SOE 8-11 June 2013. Copenhagen, Denmark; Poster EPRET-739.

132. Liu XQ, Wu BJ, Pan WH, et al. (2013): Resveratrol mitigates rat retinal ischemic injury: the roles of matrix metalloproteinase-9, inducible nitric oxide, and heme oxygenase-1. J Ocul Pharmacol Ther 29: 33-40.

133. Bríkenhielm E, Cao R, Cao Y (2001): Suppression of angiogenesis, tumor growth, and wound healing by resveratrol, a natural compound in red wine and grapes. FASEB J 15: 1798-1800.

134. Hua J, Guerin KI, Chen J, et al. (2011): Resveratrol inhibits pathologic retinal neovascularization in Vldlr(-/-) mice. Invest Ophthalmol Vis Sci 52: 2809-2816.

135. Losso JN, Truax RE, Richard G (2010): Trans-resveratrol inhibits hyperglycemia-induced inflammation and connexin downregulation in retinal pigment epithelial cells. J Agric Food Chem 58: 8246-8252.

136. Seong H, Ryu J, Jeong JY, et al. (2015): Resveratrol suppresses VEGF secretion via inhibition of CXC-chemokine receptor 4 expression in ARPE-19 cells. Mol Med Rep 12: 1479-84.

137. Zhang M, Li W, Yu L, Wu S (2014): The suppressive effect of resveratrol on HIF-1 alpha and VEGF expression after warm ischemia and reperfusion in rat liver. PLoS One 9: e109589.

138. Gliemann L, Schmidt JF, Olesen J, et al. (2013):Resveratrol blunts the positive effects of exercise training on cardiovascular health in aged men. J Physiol 591 (Pt20): 5047-59.

139. George J, Singh M, Srivastava AK, et al. (2011):Resveratrol and black tea polyphenol combination synergistically suppress mouse skin tumors growth by inhibition of activated MAPKs and p53. PLoS One 6: e23395.

140. Lee SH, Koo BS, Park SY, Kim YM (2015): Anti-angiogenic ffects ofresveratrol in combination with 5-fluorouracil on b16 murine melanoma cells. Mol Med Rep; DOI: 10.3892/2015.3675.

141. Ding Y, Chen ZJ, Liu S, et al. (2005): Inhibition of Nox-4 activity by plumbagin, a plant-derived bioactive naphthoquinone. J Pharm Pharmacol 57: 111-116.

142. Xu TP, Shen H, Liu LX, Shu YQ (2013): Plumbagin from Plumbago Zeylanica $\mathrm{L}$ induces apoptosis in human nonsmall cell lung cancer cell lines through NF-kB inactivation. Asian Pacific J Cancer Prev 14: 2325-2331.

143. Sinha S, Pal K, Elkhanany A, et al. (2013): Plumbagin inhibits tumorigenesis and angiogenesis of ovarian cancer cells in vivo. Int J Cancer 132: 1201-1212.

144. Aziz MA, Dreckschmidt NE, Verma K (2008): Plumbagin, a medicinal plant-derived naphthoquinone, is a novel inhibitor of the growth and invasion of hormone-refractory prostate cancer. Cancer Res 68: 9024-9032.

145. Maraldi T (2013): Natural compounds as a modulators of NADPH oxidases. Oxid Med Cell Longev Article ID 271602,10 pages http://dx.doi.org/10.1155/2013/271602.

146. Skopiński P, Radomska-Leśniewska DM, Sokolnicka I, et al. (2013): In vivo stimulatory effect of multi-component herbal remedy PADMA 28 on mitogen-induced proliferation of mice splenic lymphocytes and their chemokinetic activity. Pol J Vet Sci 4: 701-705.

147. Gieldanowski J, Dutkiewicz T, Samochowiec L, Wójcicki $\mathrm{J}$ (1992). PADMA 28 modifies immunological functions in experimental atherosclerosis in rabbits. Arch Immunol Ther Exper 40: 291-295. 
148. Cowan MM (1999): Plant products as antimicrobial agents. Clin Microbiol Rev 12: 564-582.

149. Radomska-Leśniewska DM, Skopiński P, Niemcewicz M, et al. (2013): The effect of anti-inflammatory and antimicrobial herbal remedy PADMA 28 on immunological angiogenesis and granulocytes activity in mice. Mediat Inflamm 2013; 8534475. DOI: 10.1155/2013/853475.

150. Kim EJ, Hong JE, Lim SS, et al. (2012): The hexane extract of Saussurea lappa and its active principle, dehydrocostus lactone, inhibit prostate cancer cell migration. J Med Food 15: 24-32.

151. Wang CY, Tsai AC, Peng CY, et al. (2012): Dehydrocostuslactone suppresses angiogenesis in vitro and in vivo through inhibition of AKT/GSK-3beta and mtor signaling pathways. PLoS One 7: e31195.

152. Ginsburg I, Rozenstein-Tsalkovich L, Koren E, Rosenmann H (2011): The herbal preparation Padma 28 protects against neurotoxicity in PC12 cells. Phytother Res 25: 740-743.

153. Skopińska-Różewska E, Pastewka K, Wasiutyński A, et al. (2010): The influence of herbal remedies on cutaneous angiogenesis induced in mice after grafting of human kidney cancer tissue. Centr Eur J Immunol 35: 199-203.

154. Recalde S, Garcia-Garcia L, Fernandez-Robredo P (2012): Effect of Resvega in a model of choroidal neovascularization in mice. Acta Ophthalmol 90 (s249). DOI: 10.1111/j.17553768.2012.S064.

155. Lançon A, Lizard G, Latruffe N (2012): The in vitro anti-inflammatory and anti-angiogenic potential of a new resveratrol-based formula (Resvega). Acta Ophthalmol 90 Suppl: s249. DOI: 10.1111/j.1755-3768.2012.S054.x

156. Olmiere C, Clerc A, Leconte L (2013): RESVEGA, by the presence of Resveratrol, inhibits retinal endothelial tube formation. Acta Ophthalmol 91. DOI: 10.1111/j.17553768.2013.F015.x0.

157. Shilova IV, Zhavoronok TV, Suslov NI, et al. (2006): Hepatoprotective and antioxidant activity of meadowsweet extract during experimental toxic hepatitis. Bull Exp Biol Med 142: 216-218.

158. Brien S, Lewith GT, McGregor G (2006): Devil's Claw (Harpagophytum procumbens) as a treatment for osteoarthritis: a review of efficacy and safety. J Altern Complement Med 12: 981-993.

159. Prosińska J, Sawicka T, Drozd J (2002): Investigations of the thymomimetic activity of a selected phytopharmaceutical preparation- Reumaherb tablets by flow cytometry. Acta Pol Pharm 59: 265-273.

160.Radomska-Leśniewska DM, Demkow U, Chorostowska-Wynimko J, et al. (2006): Immunotropic activity of complex herbal remedium Reumaherb. In: Naturalne i syntetyczne modulatory odpowiedzi immunologicznej i angiogenezy. Siwicki A.K, Skopińska-Różewska E, SPW EDYCJA, Olsztyn; 49-61. 